\title{
Enfermedades Emergentes y Barrera de Especies: Riesgo del Herpesvirus Equino 9
}

\author{
Emerging diseases and species barrier: the risk of equine \\ herpesvirus 9
}

\author{
Julián Ruiz-Saenz ${ }^{1}$ y Luis C. Villamil-Jimenez ${ }^{2}$ \\ 1 Facultad de Medicina Veterinaria y de Zootecnia, Universidad Nacional de Colombia-Sede Bogotá. \\ julianruizsaenz@gmail.com \\ 2 Facultad de Medicina Veterinaria, Universidad de la Salle. lvillamil@lasalle.edu.co
}

Recibido 7 Mayo 2008/Enviado para Modificación 26 Octubre 2008/Aceptado 12 Noviembre 2008

\section{RESUMEN}

El salto en la barrera de especies es responsable de gran parte de las enfermedades emergentes y reemergentes en el mundo; en la actualidad, no están completamente esclarecidos los mecanismos involucrados en la restricción de un agente hacia un(os) hospedero determinado(s) ni en los procesos necesarios para que éste cruce la barrera de especie e invada un nuevo hospedero. Los saltos hacia nuevas especies, generalmente se manifiestan con una alta morbilidad y mortalidad en la especie nueva, acarreando grandes pérdidas económicas y en múltiples ocasiones causando pérdida de vidas humanas. Por su parte, las especies exóticas, presentes tanto en los hogares como en los parques zoológicos, se han convertido en uno de los principales factores de riesgo para la emergencia y reemergencia de enfermedades en poblaciones animales y humanas, y por tanto se hace necesario que se evalúen las infecciones que puedan tener potencial para realizar el llamado "salto" y acarrear graves consecuencias tanto para poblaciones animales como humanas. Utilizando el Herpesvirus equino- 9 como ejemplo, el presente ensayo pretende crear conciencia sobre el riesgo existente de un salto en la barrera de especie y las posibles implicaciones del mismo.

Palabras Clave: Herpesviridae, riesgo, virosis, (fuente: DeCS, BIREME)

\section{ABSTRACT}

Jumping the species barrier is responsible for a large part of emerging and reemerging diseases around the world; however, the mechanisms involved in restricting an agent to a given host are currently not fully understood, nor what is necessary to leap the species barrier to invade a new host. These leaps to new species are usually manifest by high rates of morbidity and mortality in the new species, leading to severe economic losses and sometimes causing loss of human life. On the other hand, exotic species both in homes and zoos have become one of the major risk factors for the emergence and reemergence of disease in 
human and animal populations and it has thus become necessary to assess infections which may be able to make the so called "jump" and have serious consequences for human and animal populations. This article seeks to raise awareness regarding the risk of a leap over the species barrier using the equine herpesvirus -9 as an example and its possible impli-cations.

Key Words: Emerging disease, herpesviridae, risk (source: MeSH, NLM).

$\mathbf{L}$

a interacción de las especies animales y la de éstas con la especie humana, trae como consecuencia profundos interrogantes y emergencias desde la perspectiva de la salud pública. Desde el siglo pasado ha crecido una gran preocupación debido a que enfermedades infecciosas de origen animal han extendido su rango y se han propagado a nuevas especies, nuevas áreas, nuevas poblaciones, causando graves brotes de enfermedad y en algunos casos fuertes pandemias que amenazan con golpear a la especie humana (1).

Varios interrogantes emergen frente a lo señalado: ¿qué le impide a un microorganismo de una especie infectar a otra especie diferente?, la respuesta científica se he denominado la Barrera de especies, la cual se podría definir como la dificultad o imposibilidad para que un agente infeccioso pase de una especie a otra debido a la "especialización” genética de los agentes, los cuales están adaptados a una sola o unas cuantas especies. Estas especializaciones están basadas en diferencias genéticas, metabólicas, como la presencia de receptores celulares para los virus. Esto hace que un organismo solo se pueda reproducir en una especie; sin embargo, algunos organismos pueden llegar a atacar especies similares, o no tan similares, pero que comparten alguna característica común, invadiendo nuevas especies, las cuales desencadenan una fuerte patogénesis con consecuencias graves asociadas a fenómenos de alta morbilidad y mortalidad (2). En los siguientes párrafos, usando un ejemplo concreto y síntesis de aportes experimentales, se mostrará como un agente puede ser devastador para varias especies y como la experimentación, la evaluación y la vigilancia de los agentes emergentes pueden prevenir que estos se dispersen y alcancen poblaciones susceptibles como la especie humana.

Emergencia de enfermedades y el salto en la barrera de especies

El llamado "salto" en la barrera de especies generalmente se facilita, por la invasión al hábitat del hospedero natural, y es así como los humanos han sido 
"presas" de varios agentes que han causado fuertes brotes de infección (Nipah, Hanta, etc.). La mayoría de estos agentes infecciosos pueden considerarse zoonóticos, indicando el contacto entre humanos y el portador del agente, el cual puede ser un vector (enfermedad de Lymme transmitida por garrapatas), o un vertebrado no humano (rabia transmitida por perros) (2).

La importancia epidemiológica de la transmisión de un agente infeccioso de animales a humanos, depende de factores tales como la densidad de la población hospedera infectada (como las aves de corral), la frecuencia con la cual la nueva especie susceptible (humanos) entra en contacto con los hospederos, la biología del patógeno incluido su modo de transmisión, el estatus nutricional y sanitario de las especies en contacto, la interacción de agentes potenciadotes de especie o interespecie, y la eficiencia de dispersión humano-humano. Sin embargo la variación genética del agente retoma gran importancia, si se tiene en cuenta que los patógenos no son organismos estáticos, por el contrario, corresponden a poblaciones dinámicas (especialmente los virus), las cuales presentan múltiples variantes, debidas a la exposición de dichos agentes a diferentes pre-siones selectivas (3). Adicionalmente, cuando diferentes poblaciones de agentes coexisten en una población de hospederos, se incrementa el riesgo y la probabilidad que ocurra un proceso de recombinación genética entre las poblaciones de dichos agentes (recombinación entre cepas de virus influenza en cerdos), proceso que favorecería el "salto en la barrera de especies” y permitiría la infección de humanos u otra especie animal susceptible (3).

Los herpesvirus son una familia viral altamente específica de especie (4); sin embargo, algunos de ellos pueden llegar a infectar otras especies diferentes a su hospedero natural, causando graves enfermedades y en algunos casos la misma muerte. Se ha reportado, casos de infección zoonótica con algunos herpesvirus tales como el virus B (Cercopithecine herpesvirus 1), el cual es un Alfaherpesvirus endémico en poblaciones de monos Rhesus y macacos asiáticos, los cuales no presentan sintomatología clínica y son dos de las principales especies usadas en investigación. Aunque el virus B es cercanamente relacionado al Virus herpes simplex humano-1 (HSV-1), la infección en humanos con el virus B resulta en una encefalomielitis fatal o en severa disfunción neurológica; aunque la incidencia es baja, la mortalidad de la infección supera el $70 \%$ (5).

La infección por Virus B en humanos implica el contacto directo con macacos (accidentes con agujas, mordidas, rasguños o contacto directo de las 
mucosas con fluidos); la enfermedad se caracteriza por la presentación inicial de síntomas tipo resfriado común, seguidos de signos neurológicos tales como hiperestesias, ataxia, diplopía, agitación y parálisis flácida ascendente (6). Se ha demostrado que la infección por el virus B no solo se considera un riesgo ocupacional, dado que, entre 1990 y 1992 en los Estados Unidos, se reportaron 28 casos de exposición no ocupacional a mordidas de macacos, involucrando en un $44 \%$ a infantes, ya que los macacos han cobrado gran auge como mascotas en este país (7).

Aunque las infecciones que los animales silvestres puedan transmitir a los humanos, son las de mayor preocupación para la salud pública, también han sido reportadas las infecciones antropozoonóticas con herpesvirus humanos, como cusa de mortalidad en animales. En 2002, se reportó la muerte de un "Tití" (Callithrix jacchus) luego de haber mordido a un humano; el animal desarrolló una estomatitis severa, vómito y pérdida de apetito, muriendo súbitamente, pocos días después. De las lesiones orales del primate se aisló un agente viral el cual fue caracterizado como HSV-1 (8); aunque este es un caso atípico, no es el primer reporte de estos casos, ya que previamente se había reportado la infección natural con el HSV-1 en un grupo de titíes, demostrándose infección animal-animal previa a la muerte de estos (9).

Estos datos confirman que el salto en la barrera de especies no discrimina poblaciones, y realza la importancia de la cercanía de las poblaciones y la introducción de una especie nueva en el hábitat de otra, la cual ya tiene una "sana convivencia" o enzootia con el agente; como la introducción de especies nuevas como mascotas la cual puede llegar a ser fatal.

El caso del Herpesvirus Equino tipo 9 (EHV-9)

El EHV-9 pertenece a la subfamilia Alfaherpesvirinae género Varicellovirus (4). Se aisló por primera vez en gacelas de Thompson (Gazella thomsoni), que murieron de una encefalitis fulminante en 1993 en un zoológico de Japón. De 8 gacelas, 7 murieron de dicha encefalitis, mostrando signos de enfermedad neurológica tales como mo-vimientos en círculo y espasmos, previos a la muerte; histológicamente se diagnosticó como encefalitis no supurativas (10). El agente viral aislado fue denominado Herpesvirus Gacela-1 (GHV-1); sin embargo, luego de estudios de caracterización genética, se evidenció una alta homología con herpesvirus equinos (aproximadamente $95 \%$ con los herpesvirus equinos 1 y 8 [EHV-1 y EHV-8], y $60 \%$ con el herpesvirus equino-4 [EHV$4])$, adquiriendo así el nombre actual de herpes-virus equino-9 $(10,11)$. 
Los estudios In Vivo en ratones BALB/c y en hámsteres experimentalmente infectados con el EHV-9, vía intracerebral e intranasal, mostraron un enorme potencial neuropatogénico, con síntomas neurológicos (espasmos, ataxia, comportamiento clamoroso, convulsiones, etc.) y causando la muerte de todos los animales $(10,12)$. Sin embargo, el rango de hospedero(s) natural(es) y la patogenicidad del EHV-9 era desconocida, por tanto, investigadores de la Universidad de Gifú (Japón) comenzaron a evaluar la patogenicidad y la infectividad del EHV-9 en distintas especies.

Teniendo en cuenta que era un virus relacionado los EHV-1 y EHV-4, los investigadores evaluaron la patogenicidad en potros usando un sistema aerógeno de inoculación. La infección se caracterizó por un incremento de la temperatura, encefalitis no supurativa y neumonía acompañada de excreción de virus en cavidad nasal, además de provocar una viremia que podía ser detectada hasta el día 6 post inoculación; no se presentó mortalidad (13). Considerando la fuerte virulen-cia del EHV-9 en las gacelas versus los equinos, si un equino se encontrara infectado de manera latente, podría convertirse en una fuente de infección para otros equinos y otras especies.

Asumiendo que un caballo fuera la fuente de infección, las especies en riesgo serían animales de granja. Para evaluar la infección en rumiantes, los investigadores infectaron cabras, las cuales mostraron salivación, bruxismo y desordenes neurológicos como ataxia y convulsiones, llevando a los individuos a la muerte, horas después del inicio de la sintomatología clínica; el virus pudo aislarse de mononucleares de sangre periférica, cerebro, bulbo olfatorio, secreciones nasales y pulmones (14). Similares hallazgos se evidenciaron en cerdos inoculados por vía oral y nasal, siendo la vía nasal la ruta a través de la cual el virus puede causar enfermedad neurológica, mostrando de meningoencefalitis con cuerpos de inclusión intranucleares en células neuronales. El antígeno viral fue detectado inicialmente en células epiteliales de la cavidad nasal y células neurogliales de la cavidad olfatoria sugiriendo que el EHV-9 se replica en células epiteliales y luego alcanza el sistema nervioso central a través de la vía olfatoria $(15,16)$.

Al evaluar la infección en especies domesticas, se encontró que tanto gatos como perros infectados por vía intranasal, mostraban una rápida progresión de la enfermedad con prominente sintomatología neurológica, siendo particularmente prominente ésta sintomatología en los gatos. Los animales se mostraron hiperexcitables, agresivos, con tremores y convulsiones; presentando una en- 
cefalitis supurativa fulminante caracterizada por una severa degeneración y perdida neuronal con inclusiones intranucleares $(17,18)$. Estos resultados crean una gran expectativa sobre el riesgo de infección para carnívoros salvajes y te-niendo en cuenta que perros y gatos son el principal tipo de animales de compañía, resalta la importancia de la posibilidad de que esta infección pueda llegar a afectar humanos.

Para tratar de responder la pregunta si el EHV-9 puede causar riesgos a la población humana, los investigadores usaron Titíes comunes (Callithrix jacchus), los cuales fueron inoculados intranasalmente con el EHV-9 mostrando anorexia y depresión dos días posinoculación; presentando luego signos de enfermedad neurológica, como salivación, mirada fija, convulsiones clónicas y coma. El virus se aisló de los pulmones, las glándulas salivares y los nódulos linfoides mandibulares; se encontró una encefalitis no supurativa severa caracterizada por degeneración y necrosis neuronal difusa con cuerpos de inclusión intranucleares. La fuerte formación de cuerpos de inclusión en el epitelio glandular de la mucosa olfatoria, indicó la replicación del EHV-9 en las glándulas olfatorias, el cual es luego liberado a la cavidad nasal, sugiriendo que el primate excreta grandes cantidades de virus, siendo un riesgo de infección para otros hospederos susceptibles, abriéndose así la posibilidad de infección letal en grandes primates, simios mayores y posiblemente humanos (19).

Recientemente, el EHV-9 fue reportado como una de las infecciones más comunes en cebras salvajes del Serengueti clínicamente sanas, alcanzando una seroprevalencia cercana al 60 \% (20). Lo anterior sugiere que las cebras salvajes (Equus Burchelli), pueden constituir el hospedero natural del EHV-9, llevándonos al punto más crítico: ¿podrían las cebras, uno de los animales más comunes en las colecciones zoológicas del mundo, ser la fuente de una posible epidemia con características letales para múltiples poblaciones? Solo la investigación en el ambiente y en dichas colecciones, nos dará la respuesta, ya que es posible que estas puedan llegar a ser un buen hospedero, al igual que los equinos, en los cuales el agente no tiene tan letal panorama.

Las rupturas de la barrera de especie, constituyen el origen de importantes riesgos para la salud animal y la salud pública. No obstante los avances logrados en el estudio del EHV-9, existen to-davía vacios relacionados con el grado de dispersión de la infección, en especial en las colecciones de cebras de zoológicos. La búsqueda de alternativas de prevención y control de la infección, se deben dirigir al estudio de los antivirales efectivos para tratar el HSV- 
1, los cuales han mostrado efectividad frente a otros alfaherpesvirus de importancia veterinaria, como el EHV-1 y EHV-4.

Desde la salud animal y desde la salud pública, se deben establecer las alternativas de vigilancia y control ante la eventualidad de un brote, no solo en este caso, sino en el de otros patógenos, con los cuales interactuamos al acercarnos a nuevos hábitat o al introducir diferentes especies en el nuestro.

Por último, se debe recalcar la importancia que toma en el área de la emer-gencia de infecciones, la introducción de mascotas "silvestres", las cuales, dado su comercio principalmente ilegal, constituyen una fuente importante de patógenos emergentes, que pueden llegar a convertirse en nuevas zoonosis, aumentando el espectro del denominado riesgo biológico de origen animal

\section{REFERENCIAS}

1. Feng HP. Crossing the species barrier. Nat Struct Mol Biol. 2005; 12:831.

2. Klempner MS, Shapiro DS. Crossing the Species Barrier-One Small Step to Man, One Giant Leap to Mankind. N Engl J Med 2004;350:1171-2.

3. Riedel S. Crossing the species barrier: the threat of an avian influenza pandemic. Proc (Bayl Univ Med Cent) 2006;19:16-20.

4. ICTVdB Management. 00.031.1.02.013. Equid herpesvirus 9. In: ICTVdB - The Universal Virus Database, version 4. Büchen-Osmond, C. (Ed), Columbia University, New York, US; 2006.

5. Huff JL, Barry PA. B-Virus (Cercopithecine herpesvirus 1) Infection in Humans and Macaques: Potential for Zoonotic Disease. Emerg Infect Dis. 2003;9:246-50.

6. CDC-Centers for Disease Control and Prevention. Fatal Cercopithecine herpesvirus 1 (B virus) infection following a mucocutaneous exposure and interim recommendations for worker protection. MMWR Morb Mortal Wkly Rep 1998;47:1073-6,1083.

7. Ostrowski SR, Leslie MJ, Parrott T, Abelt S, Piercy PE. B-virus from pet macaque monkeys: an emerging threat in the United States?. Emerg Infect Dis. 1998;4:117-21

8. Huemer HP, Larcher C, Czedik-Eysenberg T, Nowotny N, Reifinger M. Fatal infection of a pet monkey with Human herpesvirus. Emerg Infect Dis. 2002;8:639-42.

9. Juan-Salles C, Ramos-Vara JA, Prats N, Sole-Nicolas J, Segales J, Marco AJ. Spontaneous herpes simplex virus infection in common marmosets (Callithrix jacchus). J Vet Diagn Invest 1997:9:341-5

10. Fukushi H, Tomita T, Taniguchi A, Ochiai Y, Kirisawa R, Matsumura T, Yanai T, Masegi T, Yamaguchi T, Hirai K: Gazelle herpesvirus 1: a new neurotropic herpesvirus immunologically related to equine herpesvirus 1 . Virology 1997; 227:34-44.

11. Yanai T, Sakai T, Fukushi H, Hirai K, Narita M, Sakai H, Masegi T: Neuropathological study of gazelle herpesvirus 1 (equine herpesvirus 9) infection in Thomson's gazelles (Gazella thom-soni). J Comp Pathol 1998; 119:159-68.

12. Fukushi H, Taniguchi A, Yasuda K, Yanai T, Masegi T, Yamaguchi T, Hirai K: A hamster model of equine herpesvirus 9 induced encephalitis. J Neurovirol 2000; 6:314-9.

13. Taniguchi A, Fukushi H, Matsumura T, Yanai T,Masegi T, Hirai K: Pathogenicity of a new neurotropic equine herpesvirus 9 (gazelle herpesvirus 1 ) in horses. J Vet Med Sci 2000a; 62:215-8. 
14. Taniguchi A, Fukushi H, Yanai T, Masegi T, Yamaguchi T, Hirai K: Equine herpesvirus 9 induced lethal encephalomyelitis in experimentally infected goats. Arch Virol 2000b; 145:2619-27.

15. Narita M, Uchimura A, Kimura K, Tanimura N, Yanai T, Masegi T, Fukushi H, Hirai K: Brain lesions and transmission of experimental equine herpesvirus type 9 in pigs. Vet Pathol 2000; 37:476-9.

16. Narita M, Uchimura A, Kawanabe M, Fukushi H, Hirai K: Invasion and spread of equine herpesvirus 9 in the olfactory pathway of pigs after intranasal inoculation. $\mathrm{J}$ Comp Pathol 2001; 124:265-72.

17. Yanai T, Fujishima N, Fukushi H, Hirata A, Sakai H, Masegi T: Experimental infection of equine herpesvirus 9 in dogs. Vet Pathol 2003a; 40:263-7.

18. Yanai T, Tujioka S, Sakai H, Fukushi H, Hirai K, Masegi T: Experimental infection with equine herpesvirus 9 (EHV-9) in cats. J Comp Pathol 2003b; 128:113-8.

19. Kodama A, Yanai T, Yomemaru K, Sakai H, Masegi T, Yamada S, Fukushi H, Kuraishi T, Hattori S, Kai C: Acute neuropathogenicity with experimental infection of equine herpesvirus 9 in common marmosets (Callithrix jacchus). J Med Primatol 2007; 36:335-42

20. Borchers K, Wiik H, Frolich K, Ludwig H, East ML: Antibodies against equine herpesviruses and equine arteritis virus in Burchell's zebras (Equus burchelli) from the Serengeti ecosystem. J Wildl Dis 2005; 41:80-6. 